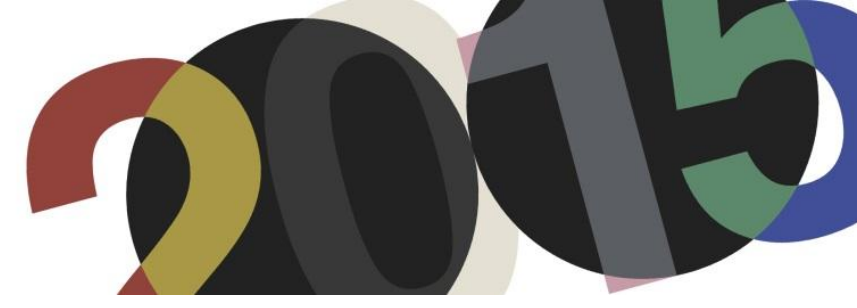

DOI: http://dx.doi.org/10.4995/LC2015.2015.732

\title{
La mirada de Pedro Vieira de Almeida a Le Corbusier: una visión desde Portugal en la segunda mitad del siglo $\mathrm{XX}$
}

\author{
T. Lopes Dias \\ Universitat Politècnica de Catalunya / Centro de Estudos de Arquitectura e Urbanismo, Universidade do Porto
}

\begin{abstract}
Resumen: Pedro Vieira de Almeida (Lisboa, 1933 - Matosinhos, 2011) es uno de los más importantes críticos y teóricos de la arquitectura en la segunda mitad del siglo XX en Portugal. En 1963, presenta en la Escuela de Bellas Artes de Oporto una tesis titulada "Ensayo sobre el espacio de la arquitectura", influida por el pensamiento de Bruno Zevi. Hasta la Revolución de los Claveles (1974), va a compaginar su práctica profesional como arquitecto con una intensa actividad crítica ejercida sobre todo en periódicos y revistas culturales. Desde sus primeros trabajos se evidencia una notable capacidad de utilizar conceptos críticos innovadores en el análisis de obras de arquitectura, lo que será fundamental en sus estudios historicos desarrollados a lo largo de su vida, dados a conocer en publicaciones y exposiciones retrospectivas sobre arquitectos clave. Este ensayo propone una reflexión sobre el legado de Le Corbusier poniendo el aciento en algunos artículos de Vieira de Almeida escritos entre 1965 y 1970, así como en la investigación que ha llevado a cabo en los últimos años de su vida. Esta lectura diacrónica pone de relieve el papel central del maestro franco-suizo en la lectura crítica de Vieira de Almeida del racionalismo, a través de las nociones por él manejadas: "estructura crítica como condición base de la creación", las vertientes poético-simbólica y mítica de la arquitectura o el concepto de carácter más instrumental de la "espesura”.
\end{abstract}

\begin{abstract}
Pedro Vieira de Almeida (Lisbon, 1933 - Matosinhos, 2011) is one of the most prominent critics and theorists of architecture in the second half of the 20th century in Portugal. In 1963, he presented at the Oporto School of Fine Arts a thesis entitled "Essay on architectural space", clearly influenced by the thoughts of Bruno Zevi. Until the Carnation Revolution (1974), he will combine his professional practice as an architect with an intense critical activity, developed mainly in newspapers and cultural magazines. Since his early work, a remarkable ability to use innovative concepts in the critical analysis of buildings have been put forth, with major consequences in his historiographical studies, developed throughout his life through publications or retrospective exhibitions on key architects. The following paper proposes a reflection on the legacy of Le Corbusier based on Vieira de Almeida's theoretical work, linking some texts written between 1965 and 1970 with his research carried out in his last years of life. This diachronic study highlights the central role of Le Corbusier in Vieira de Almeida's critical approach to rationalism, by means of notions as: "criticism as a basic condition of creation", poetic-symbolic and mythical aspects of architecture, or the more instrumental concept of "thickness".
\end{abstract}

Palabras clave: Crítica; Teoría; Pedagogía; Poética; Espesura; Ronchamp.

Keywords: Critique; Theory; Pedagogy; Poetics; Thickness; Ronchamp.

\section{Los fundamentos de una nueva mirada}

Dos meses después de la muerte de Le Corbusier, en Agosto de 1965, Pedro Vieira de Almeida publica dos pequeños artículos en revistas de arte y cultura, en los cuales subraya la necesidad de enmarcar la obra y la trayectoria profesional del maestro franco-suizo con conceptos críticos actuales. En ambos artículos destaca la "intervención lúcida" y la "coherencia operativa" de Le Corbusier y, con deseo polémico, ilustra el texto con imágenes de la capilla de Ronchamp.

En el texto publicado en Seara Nova, revista de una élite intelectual comprometida con la lucha ideológica contra la dictadura de Oliveira Salazar, relaciona las dificultades de interpretar la obra de Le Corbusier con el 
espíritu abierto y generoso del maestro, que apreciaba obras tan diversas a la suya como la de Gaudí. La fuerza expresiva y el dinamismo propagandista de su intervención habían llevado además a que esta fuera comprendida a un nivel superficial o anecdótico, sobre todo por los seguidores corbusianos más ortodoxos. "Sin embargo", añadía Vieira de Almeida, “su renovación más audaz y sus propuestas más revolucionarias siempre estuvieran sustentadas por un raciocinio crítico ejercido libremente y combativamente sobre los problemas contemporáneos. Justo ahi estaba la fuerza comunicante y catalizadora de su acción”.1.

Prácticamente al mismo tiempo, en la Revista de Artes e Letras de la prestigiosa Fundación Calouste Gulbenkian, reflexiona sobre el papel de Le Corbusier en la consolidación del Movimiento Moderno: "nadie le niega la autenticidad de su genio creativo o la vasta extensión de su ámbito de influencia, pero sí se le niega, casi sistemáticamente, la coherencia operativa y la posibilidad de dejar un legado, a nivel metodológico y ético, capaz de permanecer actual”. Tal como el título del artículo nos sugiere, es exactamente lo que él va a defender: "Le Corbusier, un arquitecto coherente"2.

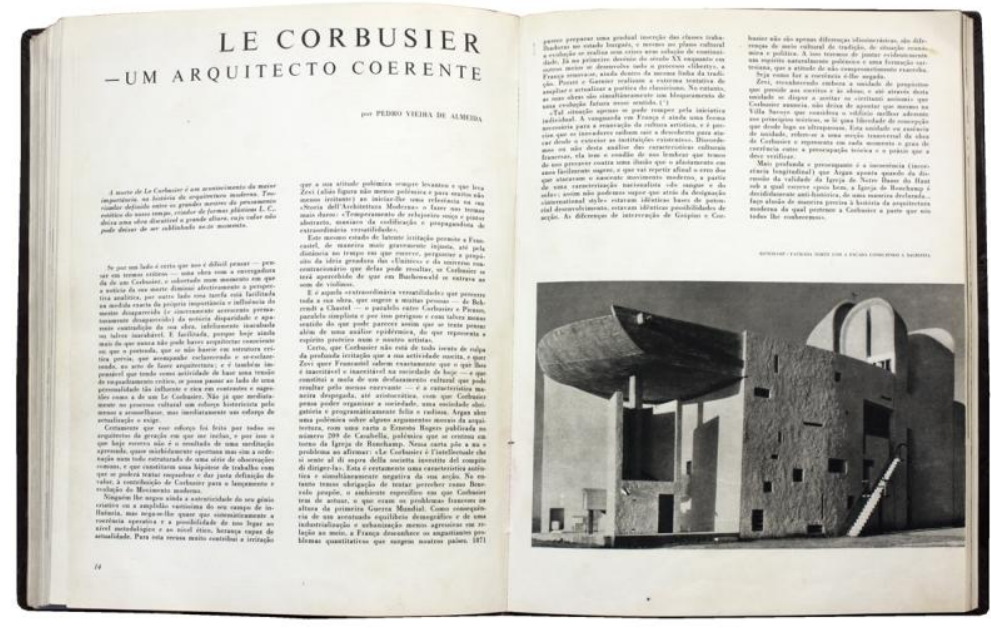

1. Artículo de Pedro Vieira de Almeida publicado en Octubre de 1965 (Colóquio: Revista de Artes e Letras, №35, pp.14-15)

Su idea de coherencia es distinta de la que está en la base de la discusión entre Ernesto N. Rogers y Giulio Carlo Argan a propósito de Ronchamp. Argan señala una contradicción no sólo entre las formas curvas, casi biomórficas, de la capilla y el muro sur de cariz neoplástico, sino también de la propia obra dentro de la historia de la arquitectura moderna ${ }^{3}$. Vieira de Almeida, por su parte, exige otros métodos de observación crítica: " $L a$ coherencia de Le Corbusier es una coherencia de intervención. Asumiendo una actitud pedagógica mucho más ambiciosa que la de Gropius, y con los riesgos que ella misma implica, Le Corbusier propone intervenir en la evolución de la arquitectura moderna con sucesivas contribuciones que pueden ser dispares entre sí - y lo son ciertamente -, pero cuya validez es llamar la atención de los arquitectos para sucesivos problemas que la evolución de las circunstancias va descubriendo (...). La coherencia de Le Corbusier es una lucha permanente contra la pérdida y la degradación semántica de los lenguajes" "4.

\footnotetext{
${ }^{1}$ Almeida, Pedro Vieira de: "Le Corbusier”. En Seara Nova. Octubre 1965, № 1440. Lisboa. p.304.

${ }^{2}$ Almeida, Pedro Vieira de: "Le Corbusier - um arquitecto coerente". En Colóquio: Revista de Artes e Letras. Octubre de 1965, No 35. Lisboa: Fundação Calouste Gulbenkian, pp.14-18.

${ }^{3}$ Rogers, Ernesto N.: "Il metodo di Le Corbusier e la forma della 'Chapelle de Ronchamp'”. En Casabella-Continuitá. Septiembre/ Octubre de 1955, № 207. Milano: Mondadori. Argan, Giulio Carlo: "La chiesa di Ronchamp (Lettera a Ernesto Rogers)". En Casabella-Continuitá, Enero/ Febrero de 1956, № 209. Milano: Mondadori.

${ }^{4}$ Almeida, Pedro Vieira de: "Le Corbusier - um arquitecto coerente". Op. cit. p.14.
} 
Esta propuesta de relectura crítica debe ser analizada tanto en el contexto portugués como en el contexto internacional, donde las críticas de Argan van a encontrar eco en otros historiadores como Nikolaus Pevsner, Bruno Zevi o Sigfried Giedion.

\section{Ronchamp: ¿una traición?}

Para aclarar el carácter polémico de los dos artículos de Vieira de Almeida hay que tener en cuenta que desde 1957 un activo grupo de su generación llevaba a cabo, en la revista Arquitectura de Lisboa, una intensa crítica a los principios del urbanismo y a los cánones formales de la arquitectura de entreguerras. Lejos parecía estar el momento de unanimidad vivido en el Congreso Nacional de Arquitectura (Lisboa, 1948) donde los arquitectos más jóvenes defendían al unísono la vivienda colectiva en altura, con soluciones tipo unidades verticales dispuestas según los principios de la Carta de Atenas y utilizando el lenguage de los "cinco puntos". Diez años después, y cuando las experiencias del "nuevo urbanismo" formaban ya parte del perfil urbano de Lisboa - véase el barrio de Alvalade - Nuno Portas presenta la unidad habitacional horizontal como alternativa tanto a las concepciones de la vivienda unifamiliar (tan al gusto del régimen de Salazar) como a la singular Unité vertical ${ }^{5}$. Como ha sugerido el historiador José-Augusto França, la influencia de Le Corbusier fue, en una primera fase de la arquitectura moderna en Portugal, casi mítica. Podemos considerar igualmente que en el período en que se empieza la revisión de la modernidad (alrededor de 1956-57, con la encuesta a la arquitectura popular, la participación en el CIAM de Dubrovnik y con la renovada Arquitectura) hay un rechazo de sus propuestas igualmente mítico. En efecto, ahora como antes, las obras de Le Corbusier llegan a Portugal filtradas por otras experiencias, sobre todo brasileñas ${ }^{6}$.

El acento de Vieira de Almeida, puesto en la fuerza pedagógica de la acción llevada a cabo por Le Corbusier a lo largo de su vida (lo que él denomina infra o supra-coherencia) e ilustrado con imágenes de Ronchamp (una obra que demostraba cuán flexibles podían llegar a ser las matemáticas del Modulor), no podía sino desconcertar a sus compañeros, fuesen los jóvenes revisionistas, fuesen los maduros y convictos modernistas. Hemos mencionado ya como Vieira de Almeida hacía coincidir los proyectos más innovadores de Le Corbusier con una crítica reflexiva sin la cual no era posible el desarrollo de la arquitectura moderna. Esta es justamente la idea que va a presentar en la "página de arquitectura" del Jornal de Letras e Artes, de la que será responsable a partir de 1965 con un espacio de divulgación de problemas, de dudas y de métodos de trabajo, más que de divulgación de soluciones ${ }^{7}$. En el artículo-clave "Estructura crítica: condición base de la creación", Vieira de Almeida reescribe y profundiza lo que ya había señalado en los dos textos citados: "La conciencia de la necesidad de una base crítica y el esfuerzo por obtenerla dentro del marco de la propia actividad profesional son sin duda las más importantes marcas de una modernidad auténtica, de una definitiva madurez en la evolución de lo que se ha llamado en arquitectura el movimiento moderno", ${ }^{\text {. }}$

\footnotetext{
${ }^{5}$ Portas, Nuno: “Conceito de casa em pátio como célula social”. En Arquitectura. Enero/Febrero de 1959, No 64. Lisboa. Además de la propuesta de Adalberto Libera para el barrio de Tuscolano - unitá d'abitazione orizzontale -, presenta casaspatio del atelier ATBAT en Marruecos, de Chamberlain, Powell \& Bon en Londres y de Jorn Utzon en Dinamarca.

${ }^{6}$ Las revistas especializadas publican artículos cortos, con poca información gráfica y sin textos críticos. De los trabajos de Le Corbusier de la posguerra, serían publicados en la revista Arquitectura el plan de Chandigardh y la Unité de Marsella $\left(\mathrm{N}^{\circ}\right.$ 49 y No 50-51, 1953) y en la revista Binário la Unité de Marsella y La Tourette ( $\mathrm{N}^{\circ} 37,1961$ y № 56, 1963).

${ }^{7}$ Almeida: "Arquitectura como disciplina interdisciplinar". En Jornal de Letras e Artes, 27-10-1965. Lisboa: Ed. Lux. p.5.

${ }^{8}$ Almeida, Pedro Vieira de: "Estrutura crítica - condição base de criação". En Jornal de Letras e Artes, 12-1-1966. Lisboa: Editora Lux. p.5.
} 
El nombre de Le Corbusier surge después de estas líneas: su arquitectura, tal como la pintura de Paul Klee, demostraba en su opinión una conciencia crítica reflexiva, racional, técnica, que no conllevaba a la limitación de la creatividad ni a la esterilización de los medios expresivos. Por otra parte, esa misma conciencia, con toda la responsabilidad e idoneidad que acarrea, es exactamente lo que permite criticar la gratuidad de algunas experiencias de vanguardia, e incluso ultrapasar las vanguardias autosuficientes o ensimismadas, finalmente académicas. Sin ese ejercicio crítico, señalaba Vieira de Almeida, la arquitectura se podría volver abstracta, alienada o incluso reaccionaria. Un esfuerzo crítico que se debe desarrollar en todos los planos, obligando a que la teoría informe la práctica pero también a que sea informada por ésta, en continua interrelación. Aunque el nombre de Le Corbusier no sea mencionado ninguna vez más, podemos intuir que era el ejemplo que tenía en la mente: ¿Quién más, entre los maestros de la primera mitad del siglo XX, había reformulado su cuerpo teórico anterior? ¿Qué obras de la posguerra habían superado mejor esos principios de la nueva arquitectura que Ronchamp, La Tourette, o el Carpenter Center?

En un ambiente como el portugués, marcado hasta finales de los años cincuenta por la ausencia de producción teórica, por la intermitencia de publicaciones periódicas de arquitectura y por el equívoco de tomar la crítica como una crónica de costumbres o de gusto, la página que Vieira de Almeida idealizaba como un espacio de debate y discusión tendría naturalmente un impacto reducido. Así como su interpretación de la coherencia corbusiana - vinculada como hemos visto a una progresiva y dinámica relación entre teoría y práctica, a una dialéctica crítica indispensable cuando la disciplina rompe con el mundo cerrado y autosuficiente de la tratadística o de la manualística. En aquellos años, en Portugal, seguirían aplicándose las texturas rugosas (el béton brut o la pared encalada tipo papier-mâché) que marcaran la obra de Le Corbusier en la posguerra, pero esta - y sobre todo Ronchamp - permanecería interpretada como un duro golpe a los parámetros racionales y puristas que habían orientado las mejores propuestas de entreguerras y que con tanto coste habían llegado a Portugal $^{9}$.

Una interpretación sin duda deudora de lo que los grandes historiadores del movimiento moderno habían escrito en los años sesenta y setenta. En el prólogo a la segunda edición en castellano de Pioneros del Diseño Moderno (1962), Nikolaus Pevsner señalaba que mientras escribía este libro en los años treinta, "la arquitectura de la razón y el funcionalismo estaba en pleno movimiento en muchos países, mientras en otros iniciaba su curso promisor”, y se consideraban “fantásticos desvarios” las propuestas de Gaudí o Sant'Elia. Pero a la sazón, se veía rodeado "nuevamente por fantasías y extravagancias, y una vez más se cuestiona[ba] la validez del estilo a cuya prehistoria se dedica [ba] este libro”. Sin embargo, en las páginas finales, Pevsner asegura la actualidad de su investigación poniendo de relieve el siguiente argumento: "El Expresionismo fue un breve intervalo continuador del Gropius temprano precediendo al Gropius maduro de los edificios de la Bauhaus en Dessau (...). Ahora estamos en medio de un segundo intervalo semejante, del cual son responsables Le Corbusier (con recientes obras como la capilla de Ronchamp) y los brasileños "10. De este modo, auguraba un nuevo período de plenitud que surgiría naturalmente del ciclo lógico de períodos "románticos" seguido de otros racionales. En una de las ultimas ediciones de su célebre manual Esquema de la Arquitectura Europea, la vigencia del estilo maduro de Gropius seguirá siendo defendido frente a Ronchamp, "el más famoso y el más discutido manifiesto del nuevo irracionalismo" ${ }^{\prime 1}$.

\footnotetext{
${ }^{9}$ Cf. Tavares, Domingos: Da rua Formosa à Firmeza. Porto: Edições ESBAP, 1980.

${ }^{10}$ Pevsner, Nikolaus: Pioneros del Diseño Moderno, de William Morris a Walter Gropius, $4^{\mathrm{a}}$ ed. Buenos Aires: Ediciones Infinito, 2003 [1936, 1962]. pp.14 y 85.

${ }^{11}$ Pevsner, Nikolaus: Storia dell'architettura europea. Bari: Editori Laterza, 1966 [1943]. p.298.
} 
Por otro lado, Bruno Zevi defendía el movimiento orgánico como única posibilidad de humanizar las ecuaciones desnudas del primer Le Corbusier y de la Bauhaus. En la edición revisada y ampliada de su Historia de la Arquitectura Moderna, en 1975, añade el capítulo "La tercera época: itinerarios de los años cincuenta-setenta", donde denuncia una crisis "encarnada por los protagonistas, en especial por la prestigiosa figura de Le Corbusier”, quien había abdicado del “compromiso doctrinario y didáctico” de los cinco puntos y había inaugurado, con la capilla de Ronchamp, "un período tan rabiosamente imaginativo como incomunicable"12. En realidad, esta idea ya estaba presente en el libro de Zevi de 1960, Architectura in Nuce: la exuberancia creadora de la última etapa de Le Corbusier anula los cinco puntos, que son traicionados y casi tomados en broma en Ronchamp. Curiosamente, Zevi lo escribe en la misma página donde alerta del peligro de que "el movimiento moderno, nacido como antítesis de la academia y los estilos, caiga él mismo en la academia estilística" "13. En ambos libros, la capilla de Ronchamp es presentada como una obra inexplicable. Un grito, un terremoto, una destrucción: así se refiere a ella Zevi en el primero, a lo largo de los apartados que va revisando. Es el caso del capítulo dedicado al arquitecto franco-suizo en la sección "los maestros del período racionalista", donde escribe: “Tan sólo entre los maestros del período, Le Corbusier tiene el valor de registrar el derrumbamiento de toda esperanza de rescatar el mundo mediante la razón" "14. Ni prosa ni poesía, dirá en el segundo libro, observando que en la capilla "no se encuentra una sola fachada plausible, escolásticamente aceptable, en cuanto proporciones, ritmo, equilibrio y contraste entre huecos y macizos: estas fachadas son sinceramente feas, incompletas, aparentemente accidentales ${ }^{\text {"15. }}$.

Finalmente, Sigfried Giedion, en el ensayo introductorio a la nueva edición de Espacio, Tiempo y Arquitectura (1962) observa que el enfoque escultórico de la última etapa del maestro no puede ser tenido en cuenta como un ejemplo: "Con bastante razón, desde muchos sitios han llegado advertencias de que un edificio como Ronchamp podría ser un desastre en manos de arquitectos mediocres. El secreto de la obra de Le Corbusier está en que él es arquitecto, pintor y escultor" ${ }^{\prime \prime}$.

\section{El "tronco" de la arquitectura}

Todas estas posiciones reflejan el debate que ha irrumpido en revistas como Casabella, L'Architettura o Architectural Review y son fundamentales para enmarcar los estudios de Vieira de Almeida, que tienen un avance significativo cuando se le encarga el volumen sobre arquitectura moderna (siglo XX) en una vasta colección de Historia del Arte en Portugal. En esta obra de 1986, presenta una lectura de la producción nacional a partir de los dos modelos avanzados por Françoise Choay: el modelo progresista y el modelo culturalista. Esto le permite establecer una primera malla de entendimiento crítico que conocerá algunos ajustes, como veremos, pero que en sus líneas fundamentales se mantendrá. En esta malla, Vieira de Almeida sitúa los dos elementos de polarización que representan el conflicto latente en la evolución de la arquitectura portuguesa: Ventura Terra (1866-1919) y Raul Lino (1879-1974) ${ }^{17}$. Al mismo tiempo, es capaz de reconocer que a algunos arquitectos habrá que situarlos en una posición intermedia, pues en su obra se produce una convergencia de los dos modelos:

\footnotetext{
${ }^{12}$ Zevi, Bruno: Historia de la Arquitectura Moderna. Barcelona: Editorial Poseidon, 1980 [1950, 1975]. p.372.

${ }^{13}$ Zevi, Bruno: Architectura in Nuce: una Definición de Arquitectura. Madrid: Aguilar, 1969 [1960]. p.200.

${ }^{14}$ Zevi, Bruno: Historia de la Arquitectura Moderna. p.106.

${ }^{15}$ Zevi, Bruno: Architectura in Nuce. p.96.

${ }^{16}$ Giedion, Sigfried: "La arquitectura en los años 1960: esperanzas y temores". En Espacio, Tiempo y Arquitectura, $9^{\mathrm{a}}$ ed. Barcelona: Editorial Científico-Médica, 2009 [1941, 1962].

${ }^{17}$ Almeida, Pedro Vieira de; Fernandes, José Manuel; Maia, Maria Helena: Arquitectura Moderna. Lisboa: Edições Alfa, 1986. pp.73-90.
} 
Le Corbusier es para él un ejemplo claro. Al contrario de Choay, que lo sitúa siempre en el modelo progresista, Vieira de Almeida defiende que los vectores culturalistas siempre han estado presentes a lo largo de su trabajo, acentuándose particularmente en obras como Ronchamp.

Esta idea estaría formulada posiblemente años antes, en 1970, cuando en las líneas finales de un texto crítico incluido en el catálogo de la exposición dedicada a Raul Lino - el jefe de fila del modelo culturalista entre los arquitectos portugueses -, cita a Le Corbusier. Puede parecer insólito juntar los nombres de Raul Lino y de Le Corbusier; lo será, ciertamente, si tenemos en cuenta un análisis sintáctico. Sin embargo, el denominador común era aquí otro: la matriz poética de la arquitectura. De este modo, y no sin una irónica petición de disculpas a sus "amigos racionalistas más extremos", Vieira de Almeida termina el texto con la transcripción de lo que considera el pequeño testamento del maestro franco-suizo: “J'ai 72 ans. J'ai bâti ma première maison à 17 ans et demi et j'ai continué mes travaux parmi les aventures, les dificultés, les catastrophes et de temps a l'autre du succes. Ma recherche tout comme mes sentiments est dirigée vers ce qui est la principale valeur de la vie: la poésie. La poésie est dans le coeur de l'homme et c'est pour cela qu'il peut s'ouvrir aux richesses de la nature $" 18$.

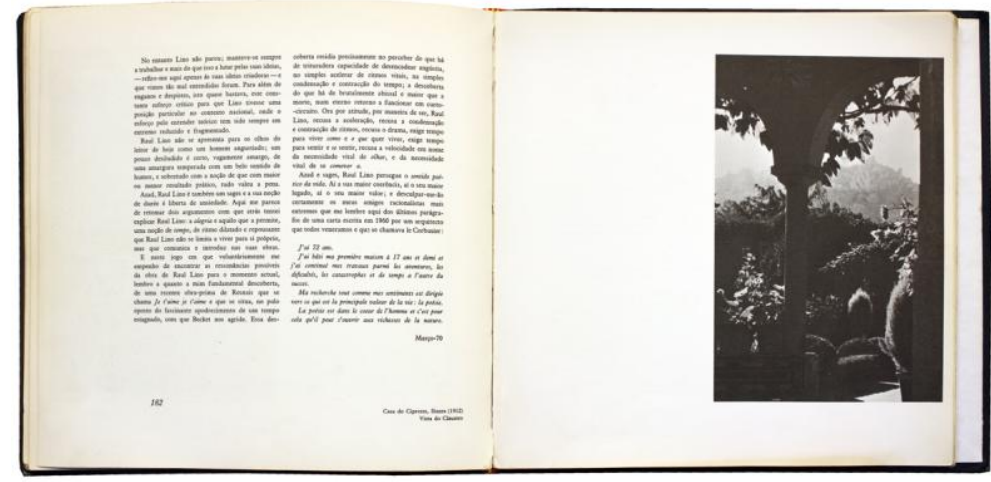

2. Catálogo de la exposición retrospectiva de Raul Lino (1970): texto de Pedro Vieira de Almeida con cita de Le Corbusier.

Se anticipa aquí un tema que sería fundamental en los estudios críticos de Vieira de Almeida: la matriz poética de la arquitectura, que consideraba adquirir un valor estructural en la obra de Le Corbusier y que funcionaría como un prisma a través del cual la historia de la arquitectura moderna podía ser cuestionada. La primacía de la interpretación del racionalismo como punto de llegada ya había sido criticada por Bruno Zevi: Pevsner, Giedion y Walter Curt Behrendt terminaran sus estudios en el racionalismo, pero sólo el último había informado de su crisis. Además señalaba el claro error en Giedion de presentar a Frank Lloyd Wright antes de Le Corbusier, y cambió ese orden en su Historia, exponiendo el organicismo wrightiano como una salida para la crisis del periodo racionalista. Pero una vez más, prevalecía el modelo dualista: la tradición del esto-o-lo-otro que Robert Venturi señaló como una limitación de la arquitectura moderna ortodoxa, y que Hugh de Cronin Hastings había trazado como una división inherente al propio Movimiento Moderno, entre una facción más clásica, racional o cristalina (de la tradición del pensamiento francés) y otra más romántica o orgánica (de la tradición del pensamiento alemán) ${ }^{19}$. Es la dualidad y la inevitabilidad del esto-o-lo-otro lo que Pedro Vieira de Almeida pretende superar cuando profundiza a lo largo de los años el concepto de espacio de la arquitectura, tema de su

\footnotetext{
${ }^{18}$ Le Corbusier, apud Almeida, Pedro Vieira de: "Raul Lino, arquitecto moderno". En Almeida, Pedro Vieira de; Carvalho, Manuel Rio; França, José-Augusto; Pimentel, Diogo: Raul Lino. Exposição retrospectiva da sua obra. Lisboa: Fundação Calouste Gulbenkian, 1970. p.182. (en francés en el original)

${ }^{19}$ Hastings, Hugh de Cronin: "Townscape: A Plea for an English Visual Philosophy". En Ockman, Joan: Architectural Culture: 1943-68. New York: Columbia Books of Architecture, Rizzoli, 1993.
} 
tesis del 1963, con obras de otros campos del conocimiento como la antropología, la etnología, la filosofía o la psicología. Su biblioteca personal nos da cuenta de estos intereses: Claude Lévi-Strauss, Jean Pierre Vernant, Gaston Bachelard, Otto F. Bollnow, Abraham Moles y Elisabeth Romer, o incluso el concepto japonés de "Ma". Son autores u obras que rellenan sus estanterías y nos ayudan a situar su particular lectura de la historia de la arquitectura, centrada sin embargo en la especificidad disciplinar del concepto de espacio: el espacio empírico de la experiencia, donde sujeto(s) y objeto(s) se interfluencian en un mismo sistema en el cual el espacio es también parte activa, y no el abstracto espacio-tiempo de la ciencia.

El esquema interpretativo que Vieira de Almeida propone resulta de la delimitación de un conjunto de tres vectores considerados en su simultaneidad: 1) una vertiente mítico-religiosa; 2) una vertiente poético-simbólica; 3) y una vertiente práctico-sociológica. El diagrama que dibuja indica que, hasta determinado momento, estos tres vectores habían llegado a formar parte inextricable de un único modelo común, de un mismo tronco de la arquitectura, y que a partir de los siglos XVII-XVIII, pero sobre todo a partir de la Revolución Industrial, uno de ellos va a ganar protagonismo absoluto: el práctico-sociológico, que con la guerra de 1914-18 y los postulados del racionalismo se convierte en una "burbuja"20. A estos tres vectores podemos asociar algunas características de los modelos de Françoise Choay: a los dos primeros, la ideología espiritual o estética, el peso del pasado y de la tradición, el predominio de la cultura, de la belleza (al cual correspondería un espacio bien circunscrito y diferenciado, con un acentuado sentido táctil) del modelo culturalista; y al último, la ideología productivista y higienista, el avance impetuoso del tiempo (al cual correspondería un espacio abierto e ilimitado, de sentido visual) del modelo progresista.

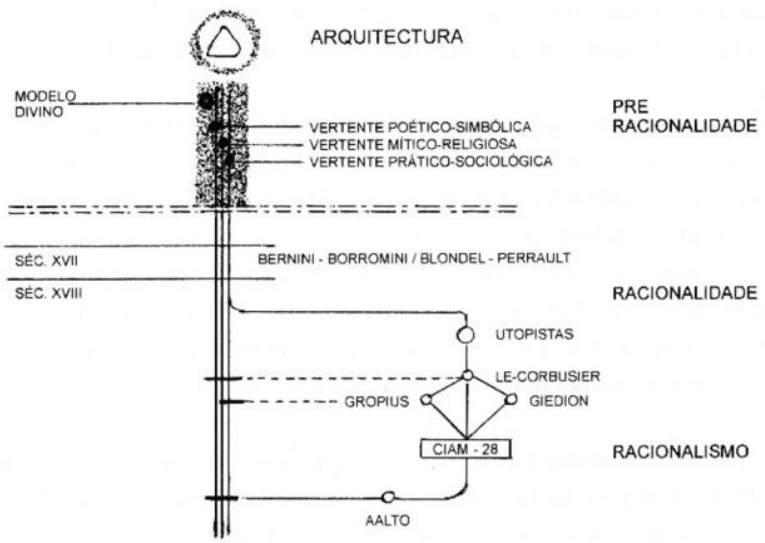

3. Diagrama de Pedro Vieira de Almeida: los tres vectores como "tronco" común, la ruptura de los siglos XVII-XVIII y la vertiente práctico-sociológica "inflada" con el racionalismo.

La complejidad de esta propuesta interpretativa, que hace hincapié en la simultaneidad de los tres vectores para una posible comprensión de la arquitectura a lo largo de la historia, no nos permite desarrollar todas sus consecuencias en este artículo. Esta breve y parcial lectura diacrónica de los estudios históricos de Vieira de Almeida debe, por otro lado, poner en relieve el papel central de Le Corbusier en la revalorización del tronco de la arquitectura, lo que proponemos hacer tomando únicamente como caso de estudio la capilla de Ronchamp.

\footnotetext{
${ }^{20}$ El término "burbuja" (borbulha) se refiere a una sobrevaloración casi obsesiva de los parámetros práctico-sociológicos. Cf. Almeida, Pedro Vieira de: O Tronco da Arquitectura. Do racionalismo como borbulha. Porto: CEAA, 2002.
} 


\section{Ronchamp: la capilla-anta y la noción de espesura}

En 2010, una relectura crítica del material compilado para la encuesta a la arquitectura popular en Portugal (1955-61) es la excusa de Pedro Vieira de Almeida para poner en práctica un vastísimo utillaje conceptual que recupera sus tempranas concepciones espacialistas y las amplía con los vectores míticos o poético-simbólicos del tronco de la arquitectura ${ }^{21}$. Esta investigación encuentra un precedente en un texto anterior donde propone aislar, como instrumento crítico, la noción de espesura en el lenguaje arquitectónico. Allí retoma la llamada de atención del historiador y arquitecto holandés Cornelis van de Ven sobre el nexo entre una arquitectura de masa y una determinada concepción de espacio interior, y reflexiona sobre la diferencia entre las aberturas en la pared espesa y las aberturas en la pared delgada: estas, observa, se limitan a dejar entrar la luz necesaria para la aprehensión del espacio, pero las primeras "controlan la luz en intensidad, tonalidad y temperatura", modelándola; y la luz modelada, concluye, resulta fundamental en el tratamiento expresivo del espacio ${ }^{22}$. La espesura es, por lo tanto, una propiedad que Vieira de Almeida asocia directamente a una noción de espacio expresivo, y "sólo el espacio expresivo permite hablar de espacio arquitectónico”, lo que le permite defender, en contra de algunos prejuicios que habían permanecido desde el International Style, que "el espacio de la arquitectura no se opone a la noción de masa - por el contrario, depende de ella",23. Naturalmente, en estos últimos trabajos suyos, Ronchamp es valorada como la obra que integra, en una magnífica dialéctica, una poética de paredes delgadas y una poética de paredes espesas.

Además va a ser frecuente su mención a esta obra de Le Corbusier como la iglesia o capilla-anta, y como es de esperar, la referencia a la raíz ancestral de la arquitectura no es gratuita. Años antes, Vieira de Almeida señalaba el dolmen (o anta) y el menhir como los dos gestos-arquetipo instauradores de toda la arquitectura. Asimismo, asociaba esta oposición a otra que Jean Pierre Vernant había señalado en su análisis del espacio en la Grecia Clásica: el espacio cerrado, protegido, de connotación femenina, asociado a la Diosa Hestia, y el espacio abierto, dinámico, de connotación masculina, asociado al Dios Hermes. De su libro Mito y Pensamiento en la Grecia Antigua, citaba: "Puede decirse que la pareja Hestia-Hermes exprime, en su polaridad, la tensión que define la representación arcaica del espacio ${ }^{24}$. Es esta tensión mítica que considera resuelta de manera magistral en Ronchamp. La utilización simultánea de una poética de paredes espesas y de una poética de paredes delgadas en el muro sur con sus "huecos habitables" y en el muro este con sus "perforaciones estrelladas" - contribuye de forma decisiva para esta tensión. Podíamos incluso arriesgar, llevando al límite la sugerencia de Vieira de Almeida, ver a Hestia y a Hermes en la sucesión de concavidades y convexidades que, en su punto de máxima tensión - cuando la cubierta convexa sobrepasa al muro naciente cóncavo - producen un espacio-transición

\footnotetext{
${ }^{21}$ Investigación coordinada por Vieira de Almeida en el Centro de Estudos Arnaldo Araújo (CEAA) de la Escola Superior Artística do Porto (ESAP), donde ejerce la docencia universitaria desde los años ochenta.

${ }^{22}$ Almeida, Pedro Vieira de: A noção de espessura na linguagem arquitectónica. Porto: CEAA, 2011 [2005].

${ }^{23}$ Almeida: Dois parâmetros de arquitectura postos em surdina. Leitura crítica do Inquérito à arquitectura regional caderno 2. Porto: CEAA, 2013 [2011]. p.26. Vieira de Almeida refiere el texto de Alfred Barr Jr. en el catálogo de la exposición del 1932 en el MOMA, en particular el siguinte pasaje: "modern architecture thinks in terms of volume of space enclosed by planes or surfaces, as opposed to mass and solidity”.

${ }^{24}$ Sobre esta cuestión, ver los siguientes textos de Pedro Vieira de Almeida: "O Dólmen e o Menhir"; "Quadro de referência das estruturas espaciais"; "Hermes - Héstia" (En Almeida: Apontamentos para uma teoria da arquitectura. Lisboa: Livros Horizonte, 2008) y "A poética de Le Corbusier - A poesia de Valéry - Uma pedagogia impossível” (En Almeida, Pedro Vieira de; Cubero, Josefina González; Trevisan, Alexandra (eds.): Ler Le Corbusier. Porto: CEAA, 2009).
} 
poéticamente ambiguo $^{25}$, ni interior ni exterior, ni cerrado ni abierto, donde se posiciona, delante de la explanada natural, un segundo altar.

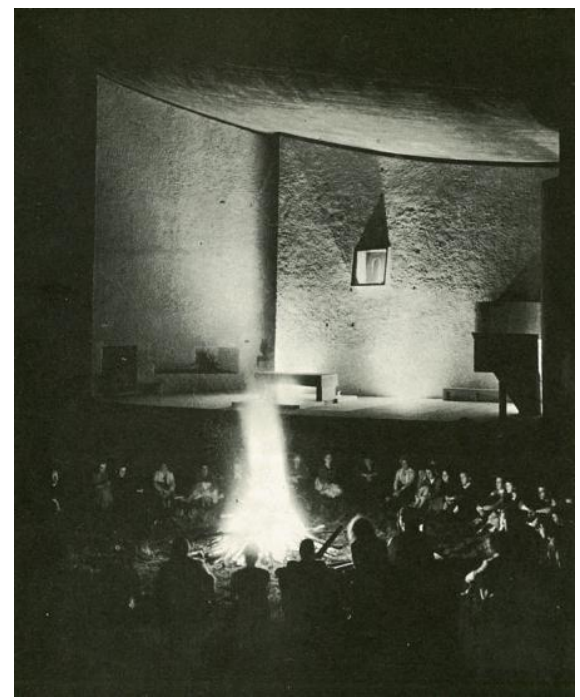

4. Fotografía nocturna de Ronchamp, con el espacio ambiguo del segundo altar al fondo (Le livre de Ronchamp. Cahiers Forces Vives/Editec, 1961)

Es importante subrayar que la metáfora visual se revela para Vieira de Almeida un valor añadido en el momento de construir una interpretación exigente y rigurosa. Con todo, ni su utilización, ni la imagen elegida, eran novedad: las metáforas fueron abundantemente utilizadas, desde el propio autor - la coquille de crabe -, hasta sus detractores - Zevi hablaba de la rudeza medievalizante de sus murallas de fortificación -, y la anta ya había sido evocada por James Stirling en su artículo del 1956, posiblemente el más influyente en apuntar el agotamiento de la base esquemática de la arquitectura moderna ${ }^{26}$. Pero en Vieira de Almeida el peso de los valores culturales e incluso míticos gana otra relevancia, pues consideraba que la tensión polarizadora de Hermes-Hestia impregnaba no solamente una representación arcaica del espacio, sino también las categorías primarias de una forma occidental del habitar, heredera aún de esos valores. De ahí su defensa de una noción de habitar hecha de intimidad y recato que cobraba la máxima importancia a la hora de equilibrar el movimiento, la velocidad, o la transparencia hermesianas de la vida moderna.

La importancia de Ronchamp es por eso doble: además de su coherencia interna, defendida como hemos visto por la articulación de dos poéticas constructivo-espaciales - una poética de paredes espesas y una poética de paredes delgadas -, es su coherencia con la propia historia de la arquitectura lo que Vieira de Almeida señalará como hallazgo fundamental. La capilla representa un cambio en la forma de Le Corbusier pensar la arquitectura - del beauxartiano sistema combinatorio de elementos a una arquitectura de instauración de valores espaciales -, y en este sentido es interpretada como un retorno al "tronco común" de la arquitectura y como un "ajuste de cuentas" con la burbuja del racionalismo de la primera mitad del siglo XX. En Ronchamp, el sistema estructural que el autor venía estudiando y aplicando desde 1914 - el sistema Domino - sigue presente, pero ahora una cal texturada uniformiza toda la superficie, como una piel arrugada que envuelve el esqueleto y los órganos. " $L a$ arquitectura no es asunto de columnas, sino de acontecimientos plásticos”, escribía Le Corbusier en ocasión de

\footnotetext{
${ }^{25}$ El espacio-transición es teorizado en su tesis del 1963, Ensaio sobre o espaço da arquitectura, y va a formar, juntamente con la espesura, los dos parámetros para una relectura crítica a la encuesta a la arquitectura popular en Portugal.

${ }^{26}$ Stirling, James: "Ronchamp: Le Corbusier's chapel and the crisis of rationalism". En Architectural Review. Marzo 1956, No 119. Londres. pp.155-161.
} 
la inauguración de Ronchamp, y "los acontecimientos plásticos no se regulan mediante fórmulas escolares o académicas; son libres e innumerables "27. Teniendo en cuenta esta arquitectura de instauración espacial y de acontecimientos plásticos, las palabras de Zevi con respecto al "furor expresionista" de Ronchamp tal vez pudieran obtener otro sentido, una vez que la arquitectura expresionista - arquitectura de masa - divulgaba precisamente estos valores. Más difícil sería encontrarle sentido a la predicción de Giedion de que "la casa maciza tradicional se disgrega en el significado de la concepción espacio-temporal”, pues Ronchamp de eso daba pruebas contrarias.

En el pensamiento de Vieira de Almeida, la arquitectura de instauración de valores espaciales, la arquitectura de base culturalista y el tronco de la arquitectura estaban fuertemente vinculados. Recordemos como resumía de forma escueta esas dos formas opuestas de hacer arquitectura que marcarían los dos polos de la arquitectura portuguesa: Ventura Terra, formado en París, desarrolla una arquitectura de composición, en la mejor tradición Beaux-Arts, donde los materiales se organizan segundo un sistema lógico; Raul Lino, formado en Alemania, desarrolla una arquitectura de instauración de valores espaciales, donde los materiales se estructuran según un sistema expresivo. En las casas macizas tradicionales de Raul Lino, los valores ancestrales del habitar se traducían arquitectónicamente en las paredes espesas, en los materiales “calientes”, en los espacios-núcleo y en los espacios-transición.

\section{Conclusión}

Para Vieira de Almeida, Ronchamp, fenómeno poético, es la materialización de la más vital y superior forma de crítica: parafraseando a T. S. Eliot, "la crítica utilizada por un experimentado y talentoso [arquitecto] en su propia obra" ${ }^{, 28}$. La coherencia pedagógico-didáctica de Le Corbusier estriba en el volte-face que representa esta obra con respecto a su primera etapa, en el reequilibrio de valores que propone y en su posicionamiento en el tronco de la arquitectura. La concepción espacial que rige esta obra - basada en un tratamiento expresivo de la luz, en la sugestión de espacios-núcleo sin interrupción de la continuidad espacial y en una compleja dialéctica interior/exterior, abierto/cerrado, cóncavo/convexo -, es para el teórico portugués una evolución necesaria del manifiesto de los "cinco puntos", grado cero de la arquitectura del siglo XX. Por otra parte, la antihistoricidad de Ronchamp, tal como la planteaba Argan, la considera como su gran fuerza pedagógica, una vez que "toda orientación pedagógica tendrá que ser antihistórica y dinámica" ${ }^{\text {29 }}$. Solo así se podían evitar la academia, los estilos, las convenciones.

En las últimas líneas del artículo de 1965, "Le Corbusier - un arquitecto coherente”, Vieira de Almeida defendía que la influencia del purismo en el maestro franco-suizo había condicionado su concepción de la arquitectura, donde la visión de los objetos predominaba sobre la visión del espacio. Chandigarh, escribe, es el ejemplo de un urbanismo "donde la distancia entre edificios, no obstante se presenten como objetos de extrema calidad, no permite la existencia de zonas de influencia que, en su interpenetración, puedan definir nuevos núcleos de espacio vital”. Esto explicará, en parte, la ausencia de Le Corbusier en su tesis del 1963 sobre el espacio de la arquitectura. Pero si la muerte de Le Corbusier había imposibilitado, a escala urbana, un "ajuste de cuentas" similar al que representó Ronchamp a pequeña escala, también es verdad que en Chandigarh ya había señales que podrían contrariar ese urbanismo de objetos dispersos. Esto mismo lo reconocería Vieira de Almeida años más tarde, cuando reflexionaba sobre el monumento de La Mano Abierta, cuya concepción coincide con la

\footnotetext{
${ }^{27}$ Le Corbusier: Modulor 2. Los usuarios tienen la palabra. Madrid: Ediciones Apóstrofe, 2005 [1955]. p.265.

${ }^{28}$ Eliot, apud Venturi, Robert: Complejidad y Contradicción en la Arquitectura. Barcelona: Gustavo Gili, 1972 [1966]. p.19.

${ }^{29}$ Almeida. "A poética de Le Corbusier - A poesia de Valéry - Uma pedagogia impossível”. Op.cit.
} 
construcción de Ronchamp: La Mano Abierta, en la dialéctica establecida entre un contenido monumental de significado universal y un acercamiento al perfil de las montañas envolventes, funcionaba como un referencial de profundidad y a través de ella se volvía presente la distancia, lo que predecía otro camino que ya no pudo ser explotado $^{30}$.

Es significativo que en el momento de arriesgar y avanzar con una definición de arquitectura, Vieira de Almeida, y a pesar de su interpretación espacialista que le impide de hablar de volúmenes reunidos bajo la luz, asuma su deuda con Le Corbusier, y en particular con lo que el maestro refería en su "testamento" como el valor principal de la vida: la poesía. Escribía Vieira de Almeida: "La arquitectura es el revelar o el instaurar poéticamente los lugares del hombre, haciendo significar la luz en una matriz espacial, jugando con el color, la materia y la forma "31. Sin entrar a fondo en la pertinencia de esta definición, podríamos preguntar, ¿no funcionaría también como una magnífica interpretación de Ronchamp?

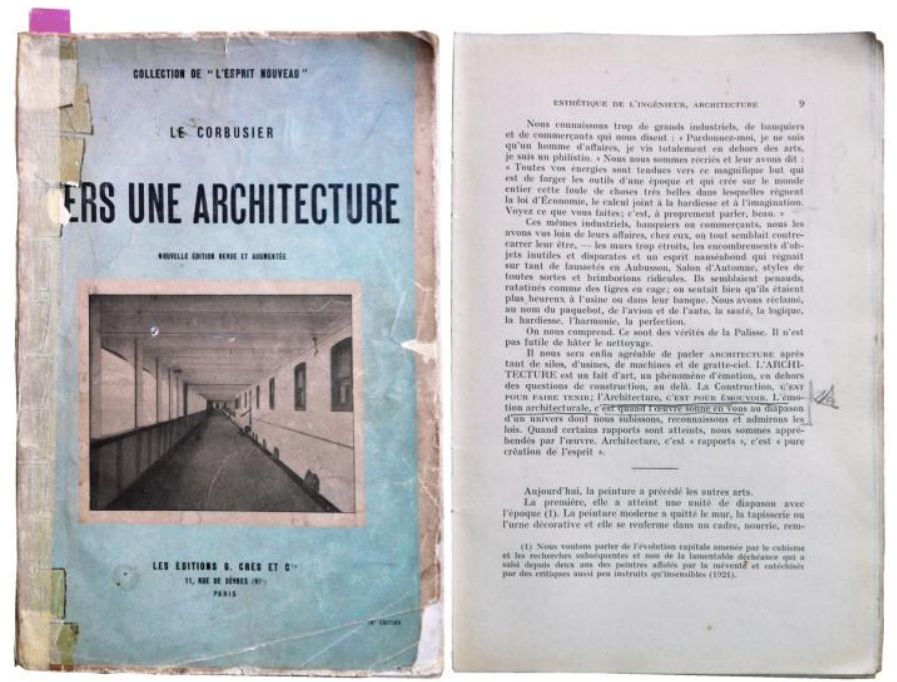

5. Ejemplar de Vers une Architecture de Pedro Vieira de Almeida: en la pagina 9, la frase de Le Corbusier "l'Architecture, c'est pour émouvoir", está subrayada.

\section{Agradecimientos}

A la Fundação para a Ciência e a Tecnologia de Portugal, por la beca FCT - DFRH - Bolsa SFRH/ BD/ 84258/ 2012, financiada por subvenciones del Ministerio de Educación y Ciencia y del Fondo Social Europeo - QREN Portugal 2007-2013. A José Àngel Sanz, Rui Jorge Garcia Ramos e Maria Helena Maia por las revisiones del texto y las sugerencias para mejorarlo.

\section{Procedencia de las imágenes}

Imagen 1: Colóquio: Revista de Artes e Letras. Octubre de 1965, № 35. Lisboa: Fundação Calouste Gulbenkian. pp.14-15. Fotografia del autor.

\footnotetext{
${ }^{30}$ Ibidem. Véase la referencia al libro de Adolf von Hildebrand, El problema de la forma en la obra de arte (1893), en el seguimiento de esta idea: “...que a través de ella se vuelva presente la distancia, en el sentido del análisis hildebrandiana de las cualidades expresivas del espacio” (p.266).

${ }^{31}$ Almeida, Pedro Vieira de: "Uma definição de arquitectura". En Almeida: Apontamentos para uma teoria da arquitectura. Op. cit. pp.33-35.
} 
Imagen 2: Almeida, Pedro Vieira de; Carvalho, Manuel Rio; França, José-Augusto; Pimentel, Diogo: Raul Lino. Exposição retrospectiva da sua obra. Lisboa: Fundação Calouste Gulbenkian, 1970. pp.182-183. Fotografía del autor.

Imagen 3: Almeida, Pedro Vieira de: O Tronco da Arquitectura. Do racionalismo como borbulha. Porto: CEAA, 2002. p.38.

Imagen 4: Le Corbusier; Petit, Jean: Le livre de Ronchamp. Cahiers Forces Vives/Editec, 1961.

Imagen 5: Archivo de Pedro Vieira de Almeida. Fotografía del autor.

\section{Bibliografía}

Almeida, Pedro Vieira de: “Le Corbusier”. En Seara Nova. Octubre 1965, No 1440. Lisboa. pp.304-305.

Almeida, Pedro Vieira de: "Le Corbusier - um arquitecto coerente". En Colóquio: Revista de Artes e Letras. Octubre de 1965, Nº 35. Lisboa: Fundação Calouste Gulbenkian. pp.14-18.

Almeida, Pedro Vieira de: “Arquitectura como disciplina interdisciplinar”. En Jornal de Letras e Artes, 27-101965. Lisboa: Editora Lux. p.5.

Almeida, Pedro Vieira de: "Estrutura crítica - condição base de criação”. En Jornal de Letras e Artes, 12-1-1966. Lisboa: Editora Lux, p.5.

Almeida, Pedro Vieira de; França, José-Augusto; Pimentel, Diogo: Raul Lino. Exposição retrospectiva da sua obra. Lisboa: Fundação Calouste Gulbenkian, 1970.

Almeida, Pedro Vieira de; Fernandes, José Manuel; Maia, Maria Helena: Arquitectura Moderna. Lisboa: Edições Alfa, 1986.

Almeida, Pedro Vieira de: O Tronco da Arquitectura. Do racionalismo como borbulha. Porto, CEAA, 2002.

Almeida, Pedro Vieira de: Apontamentos para uma teoria da arquitectura. Lisboa: Livros Horizonte, 2008.

Almeida, Pedro Vieira de; Cubero, Josefina González; Trevisan, Alexandra (eds.): Ler Le Corbusier. Porto: CEAA, 2009.

Almeida, Pedro Vieira de: A noção de espessura na linguagem arquitectónica. Porto: CEAA, 2011.

Almeida, Pedro Vieira de: Dois parâmetros de arquitectura postos em surdina. Leitura crítica do Inquérito à arquitectura regional - caderno 2. Porto: CEAA, 2013 [2011].

Argan, Giulio Carlo: "La chiesa di Ronchamp (Lettera a Ernesto Rogers)". En Casabella-Continuitá, Enero/ Febrero de 1956, N 209. Milano: Mondadori.

Giedion, Sigfried. Espacio, Tiempo y Arquitectura, 9a ed. Barcelona: Editorial Científico-Médica, 2009.

Pevsner, Nikolaus: Pioneros del Diseño Moderno, de William Morris a Walter Gropius, $4^{\mathrm{a}}$ ed. Buenos Aires: Ediciones Infinito, 2003.

Pevsner, Nikolaus: Storia dell'architettura europea. Bari: Editori Laterza, 1966.

Rogers, Ernesto Nathan: "Il metodo di Le Corbusier e la forma della 'Chapelle de Ronchamp"”. En CasabellaContinuitá. Septiembre/ Octubre de 1955, N 207. Milano: Mondadori. pp.2-6.

Stirling, James. "Ronchamp: Le Corbusier's chapel and the crisis of rationalism". En Architectural Review. Marzo 1956, No 119. Londres. pp.155-161.

Zevi, Bruno: Historia de la Arquitectura Moderna. Barcelona: Editorial Poseidon, 1980.

Zevi, Bruno: Architectura in Nuce: una Definición de Arquitectura. Madrid: Aguilar, 1969. 